\title{
Morphometric Study of Distal End of Human Dry Radii
}

\author{
Muna Kadel and Trilok Pati Thapa
}

Department of Anatomy, Nepalese Army Institute of Health Sciences, Sanobharyang, Kathmandu, Nepal

\begin{abstract}
Introduction: Radius is the lateral bone of forearm. Important parameters of its distal end include angle of radial inclination, palmar tilt, and length of radial styloid process. Morphometry of the distal end of radius is important in various clinical orthopaedic procedures such as reduction of distal radius fractures, design of distal radius prosthesis, and kinematics of the wrist joint. The aim of this study is to determine the angle of radial inclination, palmar tilt, length of styloid process, oblique width, transverse and anteroposterior diameter of distal end of human dry radii in Nepalese population.

Methods: This is a descriptive cross-sectional study conducted in the dissection hall of Department of Human Anatomy, Nepalese Army Institute of Health Sciences, Sanobhyrang, Kathmandu, Nepal from October 2019 to November 2019 after obtaining ethical approval. Total 76 human dry radii were included in the study by convenience sampling method. Angle of radial inclination, palmar tilt, length of styloid process, oblique width, transverse and anteroposterior diameter of distal end of human dry radii were studied. Data was collected and analysed by SPSS version 24 .

Results: Mean length of styloid process was $1.09 \mathrm{~cm}$. Mean anteroposterior and transverse diameter of distal end of radius was $1.88 \mathrm{~cm}$ and $2.85 \mathrm{~cm}$ respectively. Mean oblique width of distal radius was 2.82 $\mathrm{cm}$. The mean palmar tilt and angle of inclination of radius were 9.72 and 23.62 degree respectively.

Conclusions: This study provides the reference data for the anatomical alignment while treating the injuries of the distal end of radius in Nepalese population.
\end{abstract}

Key words: Forearm; Kinematics; Prostheses; Radius

Correspondence: Muna Kadel, Department of Anatomy, Nepalese Army Institute of Health Sciences, Sanobharyang, Kathmandu, Nepal, Email: muna997@hotmail.com

DOI: $10.3126 / \mathrm{mj}$ sbh.v20i1.27943

Submitted on: 2020-03-04

Accepted on: 2020-12-27

This work is licensed under creative common license:

http://creativecommons.org/licenses/by-nc-nd/4.0/ (C) MJSBH 2020 


\section{INTRODUCTION}

Radius is one of the long bones of forearm whose distal end is broader than its proximal end. Lower end possess styloid process and articular facet for ulna and carpal bones. Distal end involves in the formation of wrist and inferior radio ulnar joint. ${ }^{1}$ Four important morphometric parameters of distal end of radius include angle of radial inclination, palmar tilt, ulnar variance and length of radial styloid process. ${ }^{2}$

Distal radius fracture is one of the most common type of fractures, constituting of $25 \%$ of fractures in the paediatric population and around $18 \%$ of all fractures in the elderly people. ${ }^{3}$ Fracture reduction of distal end radius is mainly evaluated by the restoration of the prefractured value of radial inclination and palmar tilt. ${ }^{4}$ Morphometry of the distal end of radius is important in various clinical orthopaedic procedures such as reduction of distal radius fractures, design of distal radius prosthesis, and kinematics of the wrist joint. ${ }^{5}$ Decreased length of radius, increased angle of radial inclination and dorsal angulation cause significant alterations in the kinematics of the wrist joint and grip strength. Even pronation and supination depend on the initial length of radius and dorsal angulation. ${ }^{6,7}$

Most of the study of distal end of radius is done on radiographs. Radiological method of assessment using plain X-rays is considered as unreliable because of limited reproducibility. The most difficult part of this method is to determine the radial axis in the AP view. Several recent studies have shown that even minor rotational variations in wrist positioning during radiography affect these

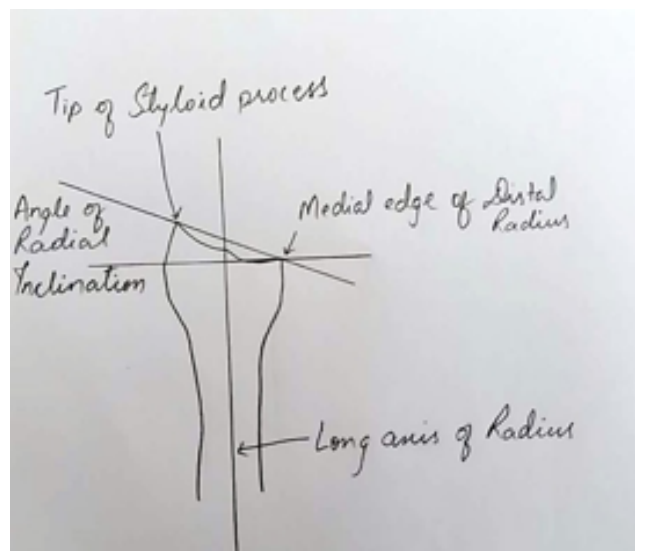

Figure1. Measurement of angle of radial inclination measurements and could adversely affect treatment decisions. ${ }^{8}$ No direct osteometric studies have been reported on the morphometry of distal radius in the Nepalese population with relevance to clinical orthopaedics. So, this study is done in dry human radii of Nepalese population. The aim of this study is to determine the angle of radial inclination, palmar tilt, length of styloid process, oblique width, transverse and antero-posterior (AP) diameter of distal end of human dry radii in Nepalese population.

\section{METHODS}

This is a descriptive cross-sectional study conducted in the dissection hall of Department of Human Anatomy, Nepalese Army Institute of Health Sciences, Sanobhyrang, Kathmandu, Nepal from October 2019 to November 2019. Ethical clearance was obtained from the Institutional Review Committee of Nepalese Army Institute of Health Sciences. Study was conducted on Nepalese human dry radii of both sides present in the dissection hall. Properly ossified radii without fracture and any structural abnormalities were included in the study. Convenience sampling technique was used to collect data. Sample size was calculated using the formula;

$$
\begin{aligned}
& \mathrm{n}=\mathrm{Z}^{2} \times \mathrm{SD}^{2} / \mathrm{e}^{2} \\
& =(1.96)^{2} \times(0.22)^{2} /(0.05)^{2} \\
& =74.37 \\
& \approx 76
\end{aligned}
$$

Where,

$\mathrm{n}=$ required sample size

$\mathrm{Z}=1.96$ at $95 \%$ confidence interval

$\mathrm{SD}=$ standard deviation (0.19) (Gupta $\mathrm{C}$ et al $2015)^{6}$

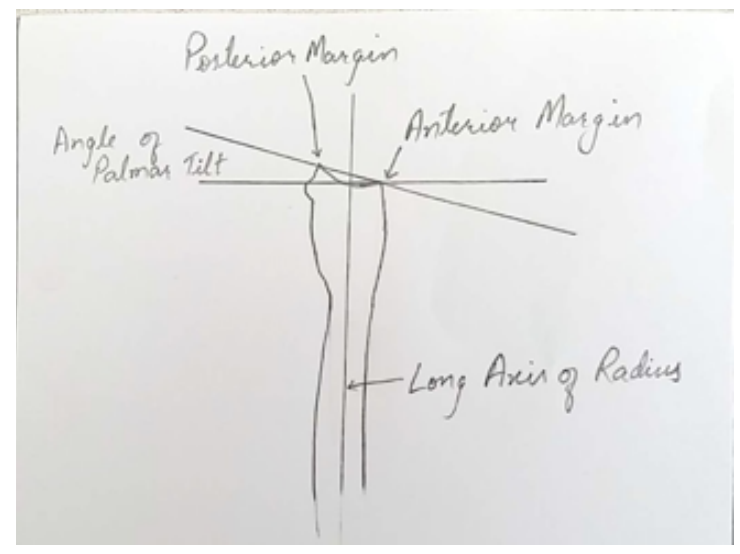

Figure 2. Measurement of angle of palmar tilt 
$\mathrm{e}=$ margin of error $(5 \%)$

Following parameters of the head of radius were measured (Figure 1,2):

- Angle of radial inclination- The angle of radial inclination was measured as the angle between a line joining the tip of radial styloid and the medial edge of the distal end of radius and a line perpendicular to the long axis of the radius.

- Length of radial styloid (SL) process- Length of radial styloid was measured as the distance between the tip of radial styloid and a perpendicular to the long axis of the radius at the level of the medial edge of distal radius.

- Widths of distal radius oblique (WDO) and transverse (WDT) - WDT was measured as the maximum width of the distal radius and WDO was measured as the oblique width of the radius along its distal margin.

- AP diameter (APD ) of distal end

- Palmar tilt (PT) - Palmar tilt is measured as an angle between, a line joining the centre of dorsal and volar margins of the articular surface of distal radius, and the perpendicular

to the long axis of the radius.

- Length of radius.

Angle of inclination and palmar tilt were measured using a long armed goniometer. Other measurements were taken with the help of digital vernier caliper of accuracy of $0.01 \mathrm{~mm}$. All the observations were recorded and tabulated. The data was analysed with the help of SPSS version 20 software. The descriptive data analysis was done to

Table 1. Various parameters of distal end of radius

\begin{tabular}{|l|r|r|r|r|}
\hline Parameters & Minimum & Maximum & Mean & $\begin{array}{c}\text { Std. } \\
\text { Deviation }\end{array}$ \\
\hline $\begin{array}{l}\text { SL } \\
(\mathrm{cm})\end{array}$ & 0.70 & 1.40 & 1.09 & 0.17 \\
\hline APD (cm) & 1.49 & 2.11 & 1.88 & 0.14 \\
\hline RA (egree) & 17.00 & 31.00 & 23.62 & 3.1 \\
\hline WDT (cm) & 2.05 & 3.27 & 2.85 & 0.26 \\
\hline WDO (cm) & 2.30 & 3.40 & 2.82 & 0.27 \\
\hline PT (degree) & 2.00 & 17.00 & 9.27 & 3.16 \\
\hline $\begin{array}{l}\text { L } \\
(\mathrm{cm})\end{array}$ & 23.08 & 25.4 & 20.0 & 1.29 \\
\hline
\end{tabular}

find mean and standard deviation of different parameters of distal end of radius. Student ' $t$ ' test was used to compare the means of right and left side. $\mathrm{P}$ value $<0.01$ was considered statistically significant.

\section{RESULTS}

SL: Length of styloid process, APD: AP Diameter, WTD: Transverse Diameter, WDO: Oblique width of distal end, RA: Angle of radial inclination, PT: Palmar tilt, L: Length of Radius. Maximum, minimum and mean value of various parameters of distal end of radius is given in table 1.

Comparison of means of distal radial parameters between right and left side is given in the table 2 . Length of styloid process between right and left side are statistically significant.

\section{DISCUSSION}

The morphometric parameters of distal end of radius vary among the races. ${ }^{9}$ In the clinical practice, most of the orthopaedic surgeons use the

Table 2. Morphometric parameters of distal radius on right and left side

\begin{tabular}{|c|c|c|c|c|}
\hline Parameters & Side & Mean & SD & $\begin{array}{c}P \\
\text { value }\end{array}$ \\
\hline \multirow{2}{*}{$\begin{array}{l}\text { RA } \\
\text { (Degree) }\end{array}$} & Right & 24.4545 & 2.64984 & \multirow[t]{2}{*}{0.071} \\
\hline & Left & 22.7619 & 3.28489 & \\
\hline \multirow{2}{*}{$\begin{array}{l}\text { SL } \\
(\mathrm{cm})\end{array}$} & Right & 1.0262 & 0.17293 & \multirow[t]{2}{*}{0.008} \\
\hline & Left & 1.8859 & 0.15837 & \\
\hline \multirow{2}{*}{$\begin{array}{l}\text { WTD } \\
(\mathrm{cm})\end{array}$} & Right & 2.8741 & 0.22504 & \multirow[t]{2}{*}{0.934} \\
\hline & Left & 2.8177 & 0.28867 & \\
\hline \multirow{2}{*}{$\begin{array}{l}\text { WDO } \\
(\mathrm{cm})\end{array}$} & Right & 2.9182 & 0.25567 & \multirow[t]{2}{*}{0.474} \\
\hline & Left & 2.7238 & 0.24679 & \\
\hline \multirow{2}{*}{$\begin{array}{l}\text { APD } \\
(\mathrm{cm})\end{array}$} & Right & 1.8859 & 0.15837 & \multirow[t]{2}{*}{0.015} \\
\hline & Left & 1.8823 & 0.12983 & \\
\hline \multirow{2}{*}{$\begin{array}{l}\text { PT } \\
\text { (Degree) }\end{array}$} & Right & 9.61 & 3.00 & \multirow[t]{2}{*}{0.474} \\
\hline & Left & 8.90 & 3.40 & \\
\hline \multirow{2}{*}{$\begin{array}{l}\mathrm{L} \\
(\mathrm{cm})\end{array}$} & Right & 23.06 & 1.36 & \multirow[t]{2}{*}{0.963} \\
\hline & Left & 23.08 & 1.242 & \\
\hline
\end{tabular}


Table 3. Comparisons of the different parameters of distal radius

\begin{tabular}{|c|c|c|c|c|c|}
\hline Parameters & Present study & $\begin{array}{c}\text { Gupta et al } 2015 \\
\text { (Indian } \\
\text { Cadaveric } \\
\text { study) }\end{array}$ & $\begin{array}{l}\text { Mishra et al } 2016 \\
\text { (Indian } \\
\text { radiological study) }\end{array}$ & $\begin{array}{l}\text { Gartland and } \\
\text { Werley } 1951\end{array}$ & $\begin{array}{l}\text { Wernwer et al., } \\
1992\end{array}$ \\
\hline $\begin{array}{l}\text { Angle of radial } \\
\text { inclination (degree) }\end{array}$ & $\begin{array}{l}23.62 \\
(\text { range : } 17-31)\end{array}$ & $\begin{array}{l}\text { Left side }-24.0 \\
\text { Right side }-25.6\end{array}$ & $\begin{array}{l}23.27 \\
\text { (range: } 11.3-42.1)\end{array}$ & $\begin{array}{l}23.27 \\
\text { (range: } 11.3-42.1)\end{array}$ & 30 \\
\hline Palmar tilt (degree) & $\begin{array}{l}9.27 \\
\text { (range: } 2 \text { - 17) }\end{array}$ & Not reported & $\begin{array}{l}10.07 \\
\text { (range: } 1-16.9)\end{array}$ & $\begin{array}{l}11 \\
\text { (range: } 1 \text { - 21) }\end{array}$ & 6 \\
\hline $\begin{array}{l}\text { Length of styloid } \\
\text { process }(\mathrm{cm})\end{array}$ & 1.09 & 0.98 & Not reported & Not reported & \\
\hline
\end{tabular}

reference values of Gartland and Werley as a standard value to treat the distal end radius fracture due to lack of available data of country's population. ${ }^{10}$ So this study has been done to achieve the data of Nepalese population.

In our study, the radial inclination is $24.45^{\circ}$ which is similar to the study of Schuind et al. and Mishra P K et al. ${ }^{4,11}$ Cadaveric study of Werner et al. have found significantly higher values of radial inclination. ${ }^{12}$ Comparisons of the different parameters of distal radius between different studies are done in table 3.

Palmar tilt ranged from 2 to 17 degree in this study which was similar to the findings by Mishra et al (1-16.9 degree). ${ }^{12}$ Change in palmar tilt due to distal radial fracture leads to radiocarpal instability. Mean length of styloid process in our study is 1.09 $\mathrm{cm}$ which is similar to the finding of Gupta et al. ${ }^{13}$

The fracture incidence of the lower end of radius prevails up to the $8-15 \%$ among all the fractures of the upper limb. ${ }^{14}$ Moreover, from the above discussion, it is evidential that the morphometric study of the lower radius has an utter importance during the evaluation and treatment of the injuries involving the wrist area. The distinct apprehension of the normal distribution of morphometry in a population (racial) group is utmost need for the clinical practice. Hence, probably the study over the very large population, with racial consideration and comparing the radiographic and cadaveric morphometric parameters would be better to define the normal parameters of distal end of radius in Nepalese population.

\section{CONCLUSIONS}

This study may provide a scope for further analytical research in the Nepalese population. Moreover, the data may also be used as a reference data for the anatomical alignment during surgical corrections of injuries of the distal end of radius in Nepalese population.

\section{ACKNOWLEDGEMENTS}

I would like to acknowledge the department of anatomy, Nepalese Army Institute of Health Sciences, Sanobharyang, Kathmandu, Nepal for their support.

To cite this article: Kadel M, Thapa TP. Morphometric Study of Distal End of Human Dry Radii. MJSBH. 2021;20(1):36-40.

Conflict of Interest: None declared

\section{REFERENCES}

1. Standring S, Gray H. Gray's anatomy: the anatomical basis of clinical practice. $41^{\text {st }}$ ed. Borley N R. Philadelphia: Elsevier Limited; 2016.839-40. 
2. $\mathrm{Ng} \mathrm{CY}, \mathrm{McQueen} \mathrm{MM}$. What are the radiological predictors of functional outcome following fractures of the distal radius? J Bone Jt Surg 2011;93B(2):145-50. DOI: https://doi.org/10.1302/0301-620X.93B2.25631

3. Nellans KW, Kowalski E, Chung KC. The epidemiology of distal radius fractures. Hand Clin. 2012;28(2):113-25. DOI: https://dx.doi.org/10.1016\%2Fj.hcl.2012.02.001

4. Mishra PK, Nagar M, Gaur SC, Gupta A. Morphometry of distal end radius in the Indian population: A radiological study. Indian J Orthop. 2016;50(6):610-5. DOI: https://dx.doi.org/10.4103\%2F0019-5413.193482

5. Van Eerten PV, Lindeboom R, Oosterkamp AE, Goslings JC. An X-ray template assessment for distal radial fractures. Arch Orthop Trauma Surg. 2008;128:217-21. DOI: https://dx.doi.org/10.1007\%2Fs00402-007-0391-y

6. Leung F, Ozkan M, Chow SP. Conservative treatment of intra-articular fractures of the distal radius and factors affecting functional outcome. Hand Surg. 2000;5:145-53. DOI: https://doi.org/10.1142/S0218810400000338

7. David JS. Predicting the outcome of distal radius fractures. Hand Clin. 2005;21(3);289-94. DOI: https://doi.org/ 10.1016/j.hcl.2005.03.001

8. Pennock AT, Phillips CS, Matzon JL, Daley E. The effects of forearm rotation on three wrist measurements: radial inclination, radial height and palmar tilt. Hand Surg. 2005;10(1):17-22. DOI: https://doi.org/10.1142/ S0218810405002528

9. Chan CY, Vivek AS, Leong WH, Rukmanikanthan S. Distal radius morphometry in the Malaysian population. Malaysian Orthop J. 2008;22:27-30. Available from: http://www.morthoj.org/2008v2n2/ Distal_Radius_Morphometry.pdf

10. Gartland JJ Jr., Werley CW. Evaluation of healed Colles' fractures. J Bone Joint Surg Am. 1951;33:895-907. DOI : http://dx.doi.org/10.2106/00004623-195133040-00009

11. Schuind FA, Linscheid RL, An KN, Chao EY. A normal data base of posteroanterior roentgenographic measurements of the wrist. J Bone Joint Surg Am. 1992;74:1418-29. PMID: 1429800

12. Gupta C, Kalthur SG, Malsawmzuali JC, D'souza AS. A morphological and morphometric study of proximal and distal ends of dry radii with its clinical implications. Biomed J. 2015;38:323-8. DOI: https://doi.org/ $10.4103 / 2319-4170.151033$

13. Werner FW, Palmer AK, Fortino MD, Short WH. Force transmission through the distal ulna: Effect of ulnar variance, lunate fossa angulation, and radial and palmar tilt of the distal radius. J Hand Surg Am. 1992;17:423-8. DOI: https://doi.org/10.1016/0363-5023(92)90342-m

14. Nana AD, Joshi A, Lichtman DM. Plating of the distal radius. J Am Acad Orthop Surg. 2005;13:159 71. DOI : https://doi.org/10.5435/00124635-200505000-00003 